\title{
A Geografia testemunha a História: paisagem, região e interdisciplinaridade em Marc Bloch
}

\author{
Guilherme Ribeiro
}

Introdução

No que concerne ao diálogo dos Annales com a Geografia, criou-se uma espécie de consenso historiográfico no qual uma complexa trama deu lugar a uma simples dicotomia: uma geografia vidaliana "possibilista", centrada em torno das formas engendradas pelo homem na superação das adversidades do meio, opunha-se à geografia alemã ratzeliana, que enfatizava o "determinismo" dos elementos fisicos na constituição da vida social. Apropriando-se de Vidal de la Blache e da Escola Francesa de Geografia, Bloch e Febvre eram instigados a sair dos arquivos e observar as paisagens, atentar à dinâmica das estruturas espaciais e conhecer a riqueza de seu país através de detalhadas e precisas monografias regionais.

Mas a Geografia vai além disso. Ela está mesmo no âmago da formação da escrita histórica annaliste: "Na realidade, poderiamos dizer que em certa medida foi a Geografia que engendrou a História que adotamos" ${ }^{1}$. Por conta disso, as palavras de Febvre mereceriam a reprovação do historiador brasileiro Ciro Cardoso, considerando-as "sem dúvida um exagero" 2 . O que estaria por trás de tal posição? Não causa

\footnotetext{
* Doutor em Geografia pela Universidade Federal Fluminense, com doutorado sandwich pela Université Paris-IV (Sorbonne). Professor Adjunto I de Geografia na Universidade Federal Fluminense - Campos dos Goytacazes.

${ }^{1}$ DAIX, Pierre. Fernand Braudel: uma biografia. Rio de Janeiro: Record, 1999 (1995), p.62.

${ }^{2}$ CARDOSO, Ciro Flamarion. Um historiador fala de teoria e metodologia: ensaios. Bauru: Edusc, 2005, p.144.
} 
certa estranheza o fato de um historiador de fora do âmbito dos Annales rejeitar a fala de um de seus fundadores sem, ao menos, justificá-la?

Na verdade, a postura de Cardoso é uma amostra de como a Geografia vem sendo admitida pelos estudiosos dos Annales. Em virtude de um maior interesse pela influência exercida por Berr, Simiand, Pirenne e Durkheim, Vidal aparece em um plano secundário, meio que negligenciado; cristalizou-se uma interpretação que sugere não haver mais nada a dizer sobre o assunto ${ }^{3}$. Sim, há exceções: Dosse procura examinar as consequências negativas da apropriação geográfica feita por Febvre e Bloch ${ }^{4}$; Reis afirma que a Geografia possibilitou o encontro do tempo com o espaço e serviu mesmo como instrumento de apreensão da longa duração ${ }^{5}$; Devoto tenta relacionar o papel da Geografia no desenvolvimento da metodologia annaliste ${ }^{6}$; e Pomian faz, praticamente, uma leitura da corrente a partir das questões geográficas ${ }^{7}$. De qualquer maneira, a influência da Geografia na gênese dos Annales e nos trabalhos individuais de Febvre e Bloch é um tema pouco estudado. Podem os geógrafos reclamar do descaso dado a Vidal e a outros pontos? Não, pois, se há negligência em relação à sua própria trajetória, o que dizer quando se trata da história "alheia"?

\footnotetext{
${ }^{3}$ GURIÊVITCH, Aaron. A Sintese Histórica e a Escola dos Anais. São Paulo: Perspectiva, 2003 (1991); BURKE, Peter. A Escola dos Annales (1929-1989): a Re volução Francesa da Historiografia. São Paulo: Unesp, 1997 (1990); BOURDÉ, Guy, MARTIN, Hervé. L'école méthodique. In: BOURDÉ, Guy, MARTIN, Hervé Les écoles historiques. Paris: Seuil, 1997 (1983); FONTANA, Josef. História: análise do passado e projeto social. Bauru: Edusc, 1998 (1982); FONTANA, Josef. História dos Homens. Bauru: Edusc, 2004 (2001); LE GOFF, Jacques. A história nova. In: LE GOFF, Jacques (org.). A História Nova. São Paulo: Martins Fontes, 1990 (1978)

${ }^{4}$ DOSSE, François. A História em Migalhas: dos “Annales” à Nova História. Campinas: Editora da Unicamp/Ensaio, 1992 (1987).

${ }^{5}$ REIS, José Carlos. Escola dos Annales - a Inovação em História. Rio de Janeiro: Paz e Terra, 2000

${ }^{6}$ DEVOTO, Fernando. Entre Taine y Braudel: itinerarios de la historiografia contemporánea. Buenos Aires: Editorial Biblos, 1992.

7 POMIAN, Krzysztof. L'heure des Annales. In: NORA, Pierre (dir.). Les Lieux de Mémoire. I. La République. La Nation. Les France. Paris: Gallimard, 1997 (1986). 
Isso corrobora a nossa hipótese de que existe um capítulo da história do pensamento geográfico que dificilmente poderá ser contado sem o exame da obra dos historiadores supracitados. Assim, avaliar como os Annales foram parte integrante e essencial da história do pensamento geográfico e da representação assumida pela Geografia entre as ciências vizinhas é algo que precisa ser enfatizado e no qual precisamos lançar novas luzes. Fazê-lo sob o ponto de vista de um geógrafo não significa defender qualquer tipo de corporativismo - o que seria uma atitude contraproducente -, mas sim admitir que determinadas questões que não possuem interesse para a historiografia são de extrema relevância para o pensamento geográfico. Embora sejam notórias afirmações como as que tais campos do saber se confundem, que a troca entre tais disciplinas na França sempre foi notável ou que, em meio à involução da Geografia em meados do século passado, os Annales atentaram para a análise geográfica ${ }^{8}$, o que nos interessa mesmo é a realidade das práticas e não uma definição abstrata e teórica dos campos disciplinares ${ }^{9}$. Seguir esta trilha exige uma reorientação metodológica que passa por levantar novas questões de investigação, aproximar autores, citar passagens desapercebidas, explorar e aprofundar pistas de pesquisa abertas por outrem, recuperar artigos esquecidos. Por fim, examinar os Annales nos conduzirá a uma compreensão mais adequada acerca do lugar ocupado e do papel desempenhado pela Geografia no âmbito das Ciências Humanas.

\section{A interdisciplinaridade segundo Marc Bloch}

Explorar as tramas do medievalista Bloch com a Geografia iluminará uma característica importante dos Annales:

\footnotetext{
${ }^{8}$ Respectivamente: SODRÉ, Nélson Werneck. Introdução à Geografia. Petrópolis: Vozes, 1976; QUAINI, Massimo. A Construção da Geografia Humana. Rio de Janeiro: Paz e Terra, 1983; SOJA, Edward. Geografias Pós-Modernas: a reafirmação do espaço na teoria social crítica. Rio de Janeiro: Jorge Zahar Editor, 1993 (1992).

${ }^{9}$ RONCAYOLO, Marcel. Histoire et Géographie: les fondements d'une complementarité. Annales ESC, nov.-déc., nº 6, 1989.
} 
a interdisciplinaridade. Sabemos que eles a pregavam como instrumento de renovação e aperfeiçoamento da História. Mas isso não diz tudo. A interrogação que devemos fazer é: qual a natureza dessas trocas? Reflitamos sobre um longo e emblemático trecho:

No século X de nossa era, um golfo profundo, o Zwin, recortava a costa flamenga. Depois foi tomado pela areia. $A$ que seção do conhecimento levar o estudo desse fenômeno? De imediato, todos designarão a geologia. Mecanismo de aluvionamento, papel das correntes marinhas, mudanças, talvez, no nivel dos oceanos: não foi ela criada e posta no mundo para tratar de tudo isso? Certamente. Olhando de perto, porém, as coisas não são de modo algum tão simples assim. Tratar-se-ia, em primeiro lugar, de escrutar as origens da transformação? Eis o nosso geólogo já obrigado a se colocar questões que não são mais, estritamente, de sua alçada. Pois, sem dúvida, esse assoreamento foi, pelo menos, favorecido por construções de diques, desvios de canais, secas: diversos atos do homem, resultado de necessidades coletivas e que apenas uma certa estrutura social torna possiveis. $\mathrm{Na}$ outra ponta da cadeia, novo problema: o das conseqüências. A pouca distância do fundo do golfo, uma cidade se erguia. Era Bruges. Comunicava-se com ele por um breve trajeto fluvial. Pelas águas do Zwin, ela recebia ou expedia a maior parte das mercadorias que faziam dela, guardadas todas as proporções, a Londres ou a Nova York de sua época. Vieram, cada dia mais sensiveis, os avanços da sedimentação. Bruges tentou em vão, à medida que a superficie inundada recuava, empurrar ainda mais seus portos avançados para a foz, e seus cais pouco a pouco adormeceram. Decerto essa não foi absolutamente, longe disso, a causa única de seu declínio. Age a física alguma vez sobre o social sem que sua ação seja preparada, ajudada ou permitida por outros fatores que não venham do homem? Mas, no ritmo das ondas causais, esta causa está pelo menos, não poderiamos duvidar disso, entre as mais eficazes. Ora, a obra de uma sociedade que remodela, segundo suas necessidades, o solo em que vive é, todos intuem isso, um fato eminentemente 'histórico'. Assim como as 
vicissitudes de um poderoso núcleo de trocas. Através de um exemplo bem característico da topografia do saber, eis portanto, de um lado, um ponto de sobreposição onde a aliança de duas disciplinas revela-se indispensável a qualquer tentativa de explicação; de outro, um ponto de passagem onde, depois de constatar um fenômeno e pôr seus efeitos na balança, este é, de certa maneira, definitivamente cedido por uma disciplina à outra. O que se produziu que parecera apelar imperiosamente à intervenção da história? Foi que o humano apareceu. Há muito tempo, com efeito, nossos grandes precursores, Michelet, Fustel de Coulanges, nos ensinaram a reconhecer: o objeto da história é, por natureza, o homem. (...) Já o bom historiador se parece com o ogro da lenda. Onde fareja carne humana, sabe que ali está a sua caça ${ }^{10}$.

Passagens como esta exemplificam certos elementos típicos da ciência moderna, tais como: (i) o domínio de um aspecto qualquer do empírico por uma disciplina ("A que seção do conhecimento levar o estudo desse fenômeno?”), bem como a (ii) delimitação do ofício de seu correspondente representante ("Eis o nosso geólogo já obrigado a se colocar questões que não são mais, estritamente, de sua alçada"); (iii) o imperativo de reconhecer e especificar a qualidade, a natureza deste ou daquele acontecimento, mesmo que sua argumentação esteja pautada na intuição ("a obra de uma sociedade que remodela, segundo suas necessidades, o solo em que vive é, todos intuem isso, um fato eminentemente histórico"); (iv) os limites entre as disciplinas, amiúde recordados ("depois de constatar um fenômeno e pôr seus efeitos na balança, este é, de certa maneira, definitivamente cedido por uma disciplina à outra") e (v) alicerçados no objeto ("O que se produziu que parecera apelar imperiosamente à intervenção da história? Foi que o humano apareceu (...) o objeto da história é, por natureza, o homem").

Sendo um produto do pensamento moderno, embora os Annales se esforçassem de maneira sincera em dialogar

${ }^{10}$ BLOCH, Marc. Apologia da História ou O Oficio de Historiador. Rio de Janeiro: Jorge Zahar Editor, 2001 (1949), pp.53-54, grifo nosso. 
com outras áreas do conhecimento, cada uma dessas áreas haveria de manter sua especificidade diante das outras, distintas sobretudo através do objeto e do método - duas palavras-chave da Modernidade. Portanto, os esforços dos cientistas modernos concentravam-se na busca do histórico, do geográfico, do sociológico, do antropológico, onde, se um não exclui o outro, no mínimo é diferente dele; em última instância, é a busca de uma identidade que justificaria sua existência acadêmica e científica, sublinhando (suprimindo?) a diferença entre as diversas maneiras de captação do mundo. Melhor seria, então, que escrevêssemos inter-disciplinaridade, posto que seria mais verossimil com a efetivação prática do debate.

Se o Homem é uno e indivisivel, irredutivel a um único campo do saber, assim enxergamos também a realidade empírica, "laboratório" onde a vida se desenrola e locus das inúmeras manifestações fenomênicas estudadas pelas ciências. Desta maneira, este mesmo empírico só se apresenta enquanto geográfico, histórico, sociológico, antropológico, etc., única e exclusivamente para os olhos dos geógrafos, historiadores, sociólogos e antropólogos, não havendo qualquer dado, elemento ou característica empírica que justifique tais adjetivações a não ser para os cientistas que as representam. Quando o empírico se manifesta, "acontecendo", isso não é um atributo das ciências que procuram apreendê-lo, mas sim do ser social em seu movimento de mutação. Assim, os fenômenos que ocorrem na sociedade não são exclusivos desta ou daquela ciência, embora o enfoque de uma possa se aproximar mais de um determinado acontecimento do que o de uma outra ciência afim. A título de ilustração, tomemos a Segunda Guerra Mundial. As diversas disciplinas procuram apreendê-la em sua totalidade, mas nenhuma poderá afirmar que é capaz disso senão no âmbito de suas próprias limitações, ou seja, de seu próprio campo de atuação. Aqui cabe recordarmos a advertência de Santos, consciente que "Todas as ciências são de sintese ou simplesmente não são ciências" ${ }^{11}$. Nessa perspectiva, é o olhar, a leitura de mundo,

${ }^{11}$ SANTOS, Milton. Por uma geografia nova. São Paulo: Edusp, 1978, p.98. 
as categorias e conceitos engendrados pelos cientistas que dividem, fragmentam, separam e restringem a esfera fenomênica, não existindo, deste modo, objetos de estudo dados naturalmente, nem tampouco qualquer - com o perdão da expressão - intuição "ideal" que imponha a um determinado fato esta ou aquela qualificação. Mais adiante, Bloch parece relativizar sua posição anterior, pois, conforme escreve, "A ciência decompõe o real apenas a fim de melhor observá-lo, graças a um jogo de fogos cruzados cujos raios constantemente se combinam e interpenetram. O perigo começa quando cada projetor pretende ver tudo sozinho; quando cada canto do saber é tomado por uma pátria"12. Tal afirmação não assume, contudo, ares de contradição; na verdade, ele apenas está sendo fiel ao que pensa, admitindo a interdisciplinaridade como uma condição para o melhor entendimento do fato histórico - uma vez guardadas as devidas diferenças entre a História e as demais ciências ${ }^{13}$.

"Preservar" a História e, ao mesmo tempo, abri-la às outras ciências. Não seria tarefa fácil. Preservar no sentido de resguardar sua particularidade, particularidade esta que seria afirmada no "confronto" com outras disciplinas. É este, dentre outros, um dos significados da apologia à História. Atentemos ao título de seu comentário à tese Leurs hommes et leurs travaux dans les pays de la moyenne Garonne (Agennais, Bas-Quercy) (1932) do geógrafo Pierre Deffontaines: Une étude régionale: géographie ou histoire? Após recomendar a leitura aos seus pares, reclamando que a historiografia tradicional havia negligenciado a região em tela, sua reprovação a Deffontaines é emblemática da necessidade dos Annales de uma delimitação precisa dos campos de conhecimento: como historiador, Bloch se ressentia de uma explicação mais deta-

\footnotetext{
${ }^{12}$ BLOCH, Op. Cit., 2001 [1949], p.131.

${ }^{13}$ Aguirre Rojas tem uma outra forma de ver esse ponto. Em um comentário acerca dos Annales, chega mesmo a sustentar que "Trata-se, sim, de uma intenção muito radical que aponta para o questionamento e a superação total dessa mesma divisão em disciplinas ou ciências sociais diversas, autônomas e separadas, como estratégia epistemológica de conhecimento e aproximação intelectual da realidade social". In: AGUIRRE ROJAS, Carlos Antonio. Uma História dos Annales (1921-2001). Maringá: Eduem, 2004, p.25
} 
lhada sobre o clima, o relevo e o tipo de terreno. É isso que ele espera da Geografia: conhecer o quadro natural onde se desenvolve a vida social. "Mas aqui vemos muito pouco a natureza, por fragmentos mal associados, dispostos de forma bastante artificial e que, sobretudo, deixa subsistir graves lacunas entre eles". Mas Deffontaines parece ter contrariado essa visão. Como geógrafo, seu pecado foi ter privilegiado demais o homem. E explorado-o mal, pois não se trata apenas "de uma simples questão de etiqueta", ou seja, como se pudéssemos ver o trabalho de Deffontaines sob outro rótulo e tudo estaria resolvido. Afinal, o livro também deixa a desejar no tocante aos planos histórico e social. O resultado é "uma obra demasiado híbrida"14.

Ora: a interdisciplinaridade não seria a busca em direção ao híbrido, um cruzamento entre campos distintos do saber que querem, exatamente, ultrapassar tais distinções? Não para Bloch. Não para as ciências na primeira metade do século XX. Por isso é insuficiente dizer que a interdisciplinaridade é uma traço da escrita histórica annaliste. Isto pouco esclarece. A pergunta adequada é: qual o papel que a Geografia desempenha na divisão acadêmica do trabalho proposta pelos primeiros Annales e, de posse disso, qual o conceito de interdisciplinaridade emergente a partir de então ${ }^{15}$ ? Ensaiemos algumas respostas: para Bloch, interdisciplinaridade é uma proposta de diálogo onde pontos-de-vista diversos são respeitados, embora as diferenças entre cada ciência sejam preservadas. Não é um questionamento às identidades disciplinares, mas sim um apelo a uma definição precisa de seus respectivos campos de atuação. Todavia, são ciências trabalhando em conjunto, onde cada uma contribuiria de forma específica e setorial em relação ao tema a ser pesquisado. No que concerne à Geografia, seu papel é, majoritariamente, for-

\footnotetext{
${ }^{14} \mathrm{BLOCH}$, Marc. Une étude régionale: Géographie ou Histoire? Annales d'histoire économique et Sociale, $\mathrm{n}^{\circ}$ 25, 1934, pp. 81-85.

15 Talvez por isso Wallerstein tenha confessado que devemos ir para "além dos Annales, (...), além da multidisciplinaridade, além (acima de tudo) da antinomia idiográfica-nomotética”. In: LLOYD, Christopher. As Estruturas da História. Rio de Janeiro: Jorge Zahar, 1995 [1993], p.18. 
necer uma visão de conjunto sobre as características físicas dos pays, regiões e territórios. Em seguida, seus estudos sobre a relação homem-meio são acompanhados atentamente, seja pela importância dos elementos físicos na constituição da história, seja pelas possiveis inclinações deterministas nele contidos. Por sua vez, as monografias regionais possuem o valor de revelar a diversidade física, cultural e social do território, bem como contribuem, em sua totalidade, para uma visão ampla da história da França ${ }^{16}$. Da discussão com os geógrafos, Bloch reterá ainda a questão das delimitações das fronteiras e seus critérios, a associação entre as escalas no entendimento de um dado fenômeno e a relevância da paisagem como traço histórico.

\section{Paisagem, região, escala: os papéis da Geografia no método Blochiano}

Vejamos alguns destes aspectos nas duas primeiras partes de sua longa pesquisa sobre a região da Ile-de-France, publicada na Revue de Synthèse Historique em 1912. Tendo Gallois e Longnon como referências (o que não quer dizer adesão incondicional aos mesmos), mas citando também Vidal, Demangeon e Sion, ao seguir o rastro da aparição e dos usos dos termos Ile-de-France e France, Bloch constatará duas coisas interessantes: a geologia, a arqueologia e a filologia usam a palavra Ile-de-France de formas distintas, enquanto o termo France possui não apenas limites geográficos, mas também jurídicos. Indício de sua preocupação para com a história e o traçado das fronteiras francesas, por esse motivo contestará os limites regionais administrativos do Antigo Regime, carentes de considerações geográficas. E, embora reconheça o valor da geografia popular e seu léxico, atesta sua ineficácia quando se trata de delimitar uma região em escala ampla. Aqui há uma semelhança clara com

16 "Não haverá verdadeira história da França senão onde seja feita justiça a essas profundas variedades regionais". In: $\mathrm{BLOCH}$, Marc. Régions naturelles et groupes sociaux. Annales d'histoire économique et sociale, no 17 (1932), p.498. 
Vidal: há que se apossar do conhecimento prático do senso comum, mas o cientista deve desconfiar do mesmo e superá1o. Contudo, essa não é a única similitude com o pensamento vidaliano: é dele que Bloch retira a definição da Ile-de-France como "os pays ao redor de Paris", sua unidade sendo dada pela aglomeração humana ali estabelecida ${ }^{17}$.

Quando se propõe estudar as características geográficas da Ile-de-France (subtitulo do artigo), além de observar que a região tem chamado a atenção de poucos geógrafos, Bloch volta a demonstrar sua divida com Gallois em Régions naturelles et noms de pays ${ }^{18}$ (1908). Sobre aquela, recomenda as páginas de Vidal no Tableau e o livro La géologie en chemin de fer. Description géologique du Bassin Parisien et des régions adjacentes (1888), do geólogo Albert de Lapparent. Tais referências não nos parecem casuais. Teriam elas algum significado no âmbito de como Bloch representava o conhecimento geográfico? A resposta é sim. Mencioná-las significa que o co-fundador dos Annales está diante de duas tradições acadêmicas que, embora se misturem, são dessemelhantes ${ }^{19}$ : a primeira, mais antiga e estabelecida, nos remete à prática dos geólogos que, nos séculos XVIII e XIX, recortavam o território francês segundo as prerrogativas das regiões naturais; a segunda, mais jovem e dinâmica, embora se inspire inicialmente na Geologia, logo em seguida engendrará seus próprios critérios de découpage regional - sobretudo ao incorporar a ação humana no meio e suas consequências. Entretanto, também não é acidental o fato de Bloch admiti-las - ao menos nesse artigo - num mesmo plano

\footnotetext{
${ }^{17}$ BLOCH, Marc. L'Île-de-France (Les pays autour de Paris), I. Revue de Synthèse Historique, n. 74, oct. (1912), pp.209-223.

${ }^{18}$ Ele ainda citaria outro texto de Gallois publicado nos Annales de Géographie: Sur la crue de la Seine de janvier 1910 (1911). Demonstrando estar atento à produção geográfica, faria referência à Bibliographies Annuelles des Annales de Géographie de 1910 e 1911, à tese de Jules Sion Les paysans de la Normandie Orientale (1908).

19 O fato de ter citado Auguste Longnon (historiador e professor de geografia histórica da França no Collège de France, representante de um momento em que a Geografia era dependente da História) ao lado de Gallois (representante da moderna Geografia) não é também um exemplo da presença de duas tradições coexistindo na reflexão geohistórica de Bloch?
} 
pois, a despeito das diferenças entre as vertentes em tela, a escolha das obras cria um ponto de intersecção indiscutivel: o que é o livro de Gallois senão uma defesa dos elementos físicos como sendo os primordiais na confecção das regiões? O que é o Tableau senão um Vidal cuja argumentação ainda permanece majoritariamente naturalista? Porém, se aqui vemos geógrafos e geólogos caminhando lado-a-lado, sabemos que essa não era a realidade vivida nem entre eles nem mesmo entre os próprios geógrafos: sobre o primeiro ponto, basta relembrar a oposição dos geólogos contra a autonomia da Geografia em finais do XIX. Sobre o segundo, sabe-se que, embora Vidal e Gallois dividissem a direção dos Annales de Géographie (inclusive à época em que Bloch publicara seu texto, 1912), este reteve apenas uma parcela dos ensinamentos daquele. Enquanto Vidal estava em plena tomada de consciência do mundo urbano-industrial e de seus desdobramentos na organização regional, Gallois permanecia firme no amparo às regiões naturais.

O resultado não poderia ser diferente: além de elogiar a Beauce como "perfeito exemplo de região natural" ${ }^{20}$, Bloch entende que caracterizar geograficamente a Ile-de-France não significa outra coisa senão sua descrição física: quatorze páginas dedicadas à infiltração das águas pluviais, à deposição quaternária, à erosão, à hidrografia, aos tipos de rocha e solo, aos acidentes do relevo, ao clima... Ora, por que não? Afinal, não havia admoestado Deffontaines por ter negligenciado as condições naturais da moyenne Garonne? Talvez aqui coubesse a reprovação de Braudel no prefácio da primeira edição de La Méditerranée às introduções geográficas à História que se limitavam a meras introduções, quadros estanques onde se desenrolava a atividade humana de forma alheia e independente do meio ${ }^{21}$.

Uma vez listados, os componentes acima identificados na Ile-de-France formam um mosaico que pode ser apreen-

${ }^{20}$ BLOCH, Marc. L'Île-de-France (Les pays autour de Paris), II. Revue de Synthèse Historique, n. 75, dec. (1912a), p.315.

${ }^{21}$ BRAUDEL, Fernand. La Méditerranée et le monde méditerranéen à l'époque de Philippe II. Paris: Armand Colin (1949). 
dido através do olhar. São formas, cores e volumes que desenham uma "variedade na paisagem" 2 . Porta aberta para o aprofundamento do diálogo com a Geografia, em Bloch a paisagem possui verdadeiramente um destaque heurístico. Ela não é uma noção vaga e utilizada aleatoriamente, mas um conceito no qual buscará captar o movimento da História. De início, tal como entre os geógrafos, seu impacto é essencialmente físico. Descrevê-la é mostrar a pujança da natureza e o entrelace de seus elementos. É como desenhar um quadro - mas com palavras.

Numa passagem que poderia ter sido redigida por qualquer geógrafo de então:

Os rios da Ile-de-France, que esculpiram os pays por onde atravessam, são uma de suas riquezas e um de seus charmes. Os vales que eles cavaram - com seus fundos úmidos a ocupar campinas e jardins, seus declives onde rochas diversas (cortadas, por assim dizer, como fatias) afloram uma em cima das outras (cada uma com sua cor e vegetação particular emprestadas à paisagem) e suas sinuosidades que fazem com que as inclinações mais diferentes sejam expostas em sucessão - estão dispostos nos platôs mais uniformes tal como amáveis avenidas, com perspectivas habilmente varia$\operatorname{das}^{23}$.

Mais adiante, se questiona: "Temos o direito de falar da paisagem da Ile-de-France?” Não só a resposta é positiva, mas é possivel, até, digamos assim, classificá-la. Para isso, no entanto, um aspecto não pode ser desconsiderado: o homem. Acentuando ou modificando seus traços iniciais, ele a modela. É o seu principal agente. Por isso ela é histórica. Nas entrelinhas, Bloch compartilha com os geógrafos não apenas a atração pela paisagem, mas algo mais denso: as paisagens regionais são uma das formas mais proficuas de se representar a França. A apologia à diversidade é indissociável de suas imagens, exibidas e reproduzidas com orgulho pela nação afora. O que seria uma paisagem clássica? Seria uma paisa-

\footnotetext{
${ }^{22}$ BLOCH, Op. Cit., 1912a, p.312.

${ }^{23}$ BLOCH, Op. Cit., 1912a, p.323.

18 Revista de História Regional 14(2): 7-28, Inverno, 2009
} 
gem onde o francês comum se reconheceria facilmente, num fitar de olhos. É um cimento a mais a amalgamar o cidadão francês ao seu pays e, em maior escala, sua unidade junto à pátria.

Certamente, é dificil imaginar aspectos mais diversos que os oferecidos pelas plates campagnes de la Beauce e os rochedos irregulares de Fontainebleau. Portanto, é permitido, negligenciando os aspectos assaz particulares, procurar fixar os traços comuns apresentados por tantas paisagens que se estendem sob nossos olhos? (...) Na fértil Ile-de-France, por todos os lados, campos, jardins, casas esparsas pela campanha ou reunidas em grandes aldeias, nos remetem ao trabalho humano. Mas o homem, que fez recuar a floresta, não a destruiu. Frequentemente (exceto em Beauce), ela aparece no alto de uma encosta ou para além dos longos vales do platô. Antes dela, bosques de árvores a anunciam. Os rios não são jamais torrentes: possuem ou uma calma graciosidade ou uma tranquila majestade. Estas paisagens da Ile-de-France, harmoniosas, amáveis e um pouco nobres, onde o homem nunca está ausente, e que tem, ao mesmo tempo (como os parques do século XVII), árvores, águas e largas extensões descobertas, não merecem o nome (que lha damos algumas vezes) de paisagens clássicas?24

Portanto, a paisagem traz à tona um problema de transcrição. Seu conteúdo é complexo: ultrapassa o plano do concreto visivel e remete às representações, além de admitir, de uma só vez, as dimensões espacial, temporal e social. Não obstante, num ambiente fortemente marcado pela influência do pensamento alemão, comporta ainda a não menos importante questão linguística: como traduzir o vocábulo kulturlandschaft? "Paisagem humana", sugere Bloch ser a "tradução menos inexata"25. Quatro anos mais tarde, comentando um artigo de Daniel Faucher sobre policultura antiga e afo-

${ }^{24}$ BLOCH, Op. Cit., 1912a, p.325, grifo nosso.

${ }^{25} \mathrm{BLOCH}$, Op. Cit., 1932, p.504. Duas páginas adiante, vinculando-a a um conceito caro aos Annales, Bloch falaria também em "paisagem de civilização", algo que seria vigorosamente explorado por Braudel. Ver: BRAUDEL, Fernand. Civilização Material, Economia e Capitalismo: séculos XV-XVIII. Volume 1: As Estruturas do Cotidiano. São Paulo: Martins Fontes (1996 [1979]). 
Pascal Ory

lhamento bienal na França provençal, dirá que ele acentuou o "substrato físico da paisagem humana" ${ }^{26}$. Tratar-se-ia da aceitação de um dualismo inerente ao conceito? Diríamos que sim. Independente disso, a paisagem testemunhava a História. Ela colocava o desafio do tempo, das permanências. Ela não é um acontecimento fugaz, mas uma estrutura que inclui eventos e conjunturas. Milton Santos falava do espaço, mas podemos nos apropriar da definição para assimilarmos a paisagem como uma acumulação desigual de tempos ${ }^{27}$. Ela aceita as mudanças, mas, ao mesmo tempo, as resiste; é um palimpsesto ${ }^{28}$. Abrir os olhos para seus contornos atuais era perceber parte de sua história. Álbum de fotografias a céu aberto - talvez dissesse Walter Benjamin -, a paisagem enriquecia o métier do historiador e a metodologia annaliste sob, pelo menos, três perspectivas: ampliava a noção de fonte histórica, possibilitava a materialização dos vínculos entre o presente e o passado e, especialmente, contribuía na superação da escrita histórica factual e événementielle. Bloch sabia que a arquitetura das igrejas, os instrumentos de trabalho no campo e o traçado das aldeias eram como sílabas que, uma vez associadas, permitiriam um desvendar mais lúcido e global de uma palavra chamada história. Tal como quadros dispostos num museu ou documentos guardados em arquivos, as paisagens estavam igualmente aptas à interpretação histórica. Associadas às regiões, formavam um par perfeito na constatação de que a história possuía diferentes ritmos e temporalidades. Manejadas segundo escalas distintas, mostravam que a história não era uma sequência inin-

\footnotetext{
${ }^{26} \mathrm{BLOCH}$, Marc. Les paysages agraires: essais de mise au point. Annales d'histoire économique et sociale, $\mathrm{n}^{\circ} 39$ (1936), p.269.

${ }^{27}$ SANTOS, Milton. Por uma Geografia Nova. São Paulo: Edusp (1978).

28 "O seu caráter de palimpsesto, memória viva de um passado já morto, transforma a paisagem em precioso instrumento de trabalho, pois 'essa imagem imobilizada de uma vez por todas' permite rever as etapas do passado numa perspectiva de conjunto. O autor dessas palavras, o historiador Marc Bloch, é, por assim dizer, um dos criadores dessa geografia retrospectiva da qual F. Braudel nos dá um modelo definitivo em seu La Méditerranée (1949). M. Bloch nos põe em guarda contra o risco de querer impor essa imagem - oferecida pela paisagem — "a cada etapa do passado". In: SANTOS, Milton. A Natureza do Espaço. Técnica e Tempo. Razão e Emoção. São Paulo: Edusp, 2002 (1996), pp. 106-107.
} 
terrupta de acontecimentos, mas sim um jogo de flutuações, diacronias e permanências. Onipresentes na vida cotidiana, aconselhavam ao historiador que seu oficio não se encerrava no passado. Conforme ele mesmo:

Ora, sem dúvida menos excepcionalmente do que se pensa, acontece de, a fim de atingir o dia, ser preciso prosseguir até o presente. Em certas de suas características fundamentais, nossa paisagem rural, já o sabemos, data de épocas extremamente remotas. Mas, para interpretar os raros documentos que nos permitem penetrar nessa brumosa gênese, para formular corretamente os problemas, para até mesmo fazer uma idéia deles, uma primeira condição teve que ser cumprida: observar, analisar a paisagem de hoje. Pois apenas ela dá as perspectivas de conjunto de que era indispensável partir ${ }^{29}$.

De todo modo, a questão das paisagens e das regiões está diretamente ligada às escalas - que, por sua vez, articulam-se a um outro ponto do método blochiano: a comparação. Em termos geográficos, comparar é transpor fronteiras, aproximar lugares. É impetrar explicações cujas raízes não estão à côté: outros níveis espaciais devem ser apreciados. Circunscrever um recorte espacial não significa que ele se explique por si mesmo nem, tampouco, que seus limites não sejam cambiáveis: uma das fragilidade do conceito de região não residiria precisamente nesse aspecto ${ }^{30}$ ? Havia que se privilegiar a geograficidade do fenômeno e não uma imposição apriorística. Casos como as estruturas agrárias da Europa não se enquadravam nas divisões políticas e adminis-

${ }^{29}$ BLOCH, Op. Cit., 2001 [1949], p.67.

${ }^{30}$ BLOCH, Op. Cit., 1932, p.510. Não seria essa, de alguma forma, a crítica de anos mais tarde feita por Lacoste a Vidal e seus seguidores, bem como dos sociólogos Vainer e Bourdieu à fetichização regional dos geógrafos? Ver: LACOSTE, Yves. A Geografia - isso serve, em primeiro lugar, para fazer a guerra. Campinas: Papirus (1988 [1976]); VAINER, Carlos. Região e interesses regionais: subsídios para uma discussão dos regionalismos contemporâneos no Brasil. Seminário Internacional Impasses e Perspectivas da Federação no Brasil, São Paulo, FUNDAP, 8-10 de maio (1995); BOURDIEU, Pierre. A identidade e a representação. Elementos para uma reflexão crítica sobre a idéia de região. In: BOURDIEU, Pierre. O poder simbólico. 5 $5^{\mathrm{a}}$ ed. Rio de Janeiro: Bertrand Brasil (2002 [1985]), pp.107-132. 
trativas formalmente estabelecidas ${ }^{31}$. Os mapas linguísticos desse continente revelam realidades distintas das do mapa político, p.ex. ${ }^{32}$.

Emblemático desta faceta de seu pensamento é o célebre artigo Pour une histoire comparée des sociétés européenes (1928). Permeado por raciocínios geográficos do início ao fim, desconfiava dos fatos exclusivamente locais na elucidação dos fenômenos e da "artificialidade" dos quadros nacionais ${ }^{33}$. Daí a necessidade dos estudos comparativos, "os únicos capazes de dissipar a miragem das falsas causas locais" ${ }^{34}$. É nesse sentido que enaltece a tese de André Meynier A travers le Massif Central: Ségalas, Levézou, Châtaigneraie ${ }^{35}$ (1931): pela capacidade de ter sabido extrair as articulações entre a especificidade do pequeno pays e seus laços mais gerais com o movimento da França em sua totalidade. Havia uma rede social e material (os transportes) a dinamizar as trocas no Hexágono, favorecendo tanto a utilização de novas técnicas quanto o despontar de uma nova mentalidade politica - a formação de sindicatos agrícolas ${ }^{36}$. Aqui, aparece com vigor uma questão que também recai no domínio da representação: a diversidade é exaltada não em nome de discursos separatistas, mas em nome do fortalecimento da coesão francesa. Não era esse um dos leitmotivs de Vidal de la Blache? Portanto, eis a substância, o teor político da argumentação desenvolvida por duas das modernas Ciências Humanas na

\footnotetext{
31 “Tais são alguns dos principais problemas da paisagem rural francesa. Melhor dizendo: européia. Cercas, campos irregulares, campos alongados, agricultura individual ou servidão coletiva. Com efeito, tantas realidades que se reencontram e se opõem para além de nossas fronteiras. E, sem dúvida, lá como aqui, o meio mais seguro de compreender a França é, algumas vezes, sair dela". BLOCH, Op. Cit., 1936, p.273

${ }^{32} \mathrm{BLOCH}$, Marc. Pour une histoire comparée des sociétés européenes. In: BLOCH, Marc. L'Histoire, la Guerre, la Résistance. Paris: Gallimard (2006 [1928]), p.375.

${ }^{33}$ BLOCH, Op. Cit., 2006 (1928), p.362 e 380.

${ }^{34}$ BLOCH, Op. Cit., 2006 (1928), p.363.

${ }^{35}$ Embora condene seu presentismo e, consequentemente, sua negligência em relação à história. Já com Demangeon acontece o contrário: é elogiado por associar passado e presente, concedendo à história, portanto, papel essencial. BLOCH, Op. Cit., 1932, pp.490-491.

${ }^{36}$ BLOCH, Op. Cit., 1932, p. 496.

22 Revista de História Regional 14(2): 7-28, Inverno, 2009
} 
primeira metade do século XX: sob a pena de historiadores e geógrafos, a estética das paisagens e os gêneros de vida das regiões são retratados. Todavia, por trás dessa aparente tranquilidade e de escritas tidas quase como literárias, elas formavam o quadro conceitual ideal no qual seria assentada a unidade da nação francesa ${ }^{37}$.

Pensando na comparação como uma ferramenta de conjunto, um jogo de escalas emergia diante de Bloch. Ele tinha plena consciência da riqueza de detalhes e das possibilidades de construção de uma "história total" que as pesquisas locais ${ }^{38}$ e regionais permitiam. Mas, como alguém que promovia analogias entre seu período de pesquisa e o tempo presente, sabia que as configurações espaciais da Idade Média (feudos, glebas e aldeias) eram significativamente diferentes da Idade Moderna (cidades-Estado e Estados Nacionais). Ou seja, uma vez que o desenrolar do processo

\footnotetext{
37 "Sem dúvida, um dos méritos mais surpreendentes do sr. André Meynier foi de ter sentido e feito sentir as ligações que, entre o pequeno pays que ele observava viver (de uma vida cuja aparência parecia bem particular e como que retirada) a evolução geral da França, teceu-se uma forte e sólida rede". E complementa, logo em seguida: "A influência psicológica da Grande Guerra é marcada por felizes tracos". In: BLOCH, Op. Cit., 1931, p.496. A despeito dos trinta anos que os separam, a semelhança com o Tableau de la géographie de la France (1903) é inevitável. Ambos parecem dizer que, o que a geografia e a história moldaram na longa duração, evento algum poderá desfazer. A observação de Claval é precisa: "A proposta do Tableau é mostrar como, da diversidade, pôde nascer uma unidade real. O comportamento dos franceses durante a guerra deu razão a esta visão. (...) A guerra de 1914 demonstrou o quanto a nação francesa, a despeito de sua diversidade, estava amalgamada". A consultar: VIDAL DE LA BLACHE, Paul. La France. Tableau géographique. In: RIOUX, Jean-Pierre. Tableaux de la France. Michelet, Duruy, Vidal de la Blache et Bruno. Paris: Omnibus, 2007 (1903); CLAVAL, Paul. Histoire de la Géographie française de 1870 à nos jours. Paris: Nathan, 1998, p.156.

${ }^{38}$ Quando debruçado sobre a Mle-de-France, descobre que as histórias escritas pelos beneditinos não dizem respeito apenas às lutas eclesiásticas entre ordens diferentes, mas também desvendam as particularidades locais, constituindo-se em "fontes inestimáveis para a geografia histórica". Na terceira parte desse estudo, Bloch mostra a importância da escala local, fazendo questão de definir monografias locais como aquelas em que "livros ou autores que tratam de uma história, se assim posso dizer, integral — política, religiosa, arqueológica, econômica de uma cidade ou aldeia, seja 'das origens aos nossos dias', seja, pelo menos, durante um período muito longo". Ver, respectivamente: BLOCH, Op. Cit.,1912a, p.338; BLOCH, Marc. L'Île-de-France (Les pays autour de Paris), III. Revue de Synthèse Historique, n. 76-77, fév-avr. (1913), p.146, grifo nosso.
} 
histórico passava pela criação e destruição de diversas (para usar um conceito atual) territorialidades, compreendê-lo demandava uma metodologia que levasse em conta variadas escalas de análise - sua reflexão incorporando Grã-Bretanha, Alemanha e, de forma geral, a Europa, mostra isso. Dissertando sobre a formação dos Estados europeus, a utilidade das monografias locais em seu esclarecimento e o papel da comparação, sugere uma valiosa lição metodológica para as Ciências Sociais: "Sem as pesquisas locais preliminares, vã seria a comparação; mas somente esta poderá, no bojo das causas imagináveis, reter aquelas que tiveram uma ação geral, as únicas reais"39.

\section{A contribuição da Geografia à História: o olhar critico de Bloch}

Vejamos algumas considerações levantadas em três trabalhos da década de 30: Les caractères originaux de l'histoire rural française, Régions naturelles et groupes sociaux e Les paysages agraires: essai de mise au point ${ }^{40}$. Eles ratificam a posição de Bloch junto aos geógrafos: um misto de admiração e de aguçado senso crítico. Sobre tal aspecto, não há porque julgá-lo. Não será este, talvez, o principal atributo do intelectual? A questão aqui não é essa, mas sim tensionar os campos científicos em tela dissipando o clima liso e desprovido de contradições que predomina na historiografia, arguindo a prática interdisciplinar proposta pelos Annales e avaliando suas consequências no posterior desenvolvimento da Geografia.

De qualquer maneira, o que precisa ser destacado é o interesse de Bloch pelo aporte geográfico. A História teria muito a ganhar, e sua aproximação com a Geografia tinha como objetivo principal potencializar a enunciação histórica. É assim que ele destaca o Congresso Internacional de

\footnotetext{
${ }^{39}$ BLOCH, Op. Cit, 1913, p.361.

${ }^{40} \mathrm{BLOCH}$, Marc. Les caractères originaux de l'histoire rurale française. $5^{\mathrm{a}}$ ed. $\mathrm{Pa}-$ ris: Armand Colin (1968 [1931]); BLOCH, Op. Cit., 1932; BLOCH, Op. Cit, 1936. 
Geografia relizado pela UGI em setembro de 1931, sintoma da vitalidade de uma escola "a qual os historiadores devem tantas e preciosas lições". Que exalta os geógrafos e seus estudos em grupo sobre a origem e as causas da dispersão das habitações rurais dirigidos por Demangeon ${ }^{41}$. Que se mostra leitor atento não só dos Annales de Géographie, mas também da Revue géographique des Pyrénées et du Sud-Ouest, dos Études Rhodaniennes e da Revue de Géographie Alpine ${ }^{42}$. Passado e presente uniam historiadores e geógrafos em torno de uma questão crucial na trajetória das sociedades: dadas certas condições físicas típicas de uma região, como o homem as modela, adaptando-as, por intermédio do trabalho, para o desenrolar pleno da vida social? Quais são as dificuldades e as soluções por eles encontradas para que um espaço qualquer possa tornar-se habitável? Isso implica numa série de relações e comporta inúmeras variáveis: classes de solos, escolha dos cultivos, engenhosidade dos instrumentos técnicos, divisão das propriedades, distribuição do povoamento, tipos de habitat, diferentes mentalidades coletivas ${ }^{43}$. Seria ousadia demais dizer que parte de sua agenda de pesquisas é vidaliana?

Evidentemente, este jogo não é unilateral: cabia à História, por assim dizer, corrigir as rotas e os excessos de uma corporação cuja "juventude" a deixava "ao abrigo das piores rotinas corporativas" - mal semelhante acometia etnógrafos e linguistas ${ }^{44}$. É nesse espírito de franqueza e combate intelectual que Bloch acolhe Essai sur la formation du paysage rural français (1934), de Dion: não hesita em anotar seu simplismo ao dividir a economia rural francesa em "Norte" e "Sul" e reprová-lo por ter omitido as diferenças no que tange às suas estruturas sociais e politicas ${ }^{45}$. Por estas e outras razões, "aquilo que habituou-se chamar 'geografia humana" ou "antropogeografia", cuja proposta não é outra senão a de

${ }^{41}$ BLOCH, Op. Cit., 1932, pp.489-490.

${ }^{42}$ BLOCH, Op. Cit., 1936; BLOCH, Op. Cit., 1968 (1931).

${ }^{43}$ BLOCH, Op. Cit., 1932, p.489.

${ }^{44}$ BLOCH, Op. Cit., 2001 (1949), p. 146.

${ }^{45}$ BLOCH, Op. Cit., 1936, pp.226 e 271. 
estudar as "trocas de sentido duplo"46, é algo que deve ser incentivado e acompanhado amistosamente - mas, decerto, com uma dose de prudência. Neste trecho, duas coisas podem ser observadas: primeiro, a estranheza frente às expressões geografia humana e antropogeografia, que ele mesmo faz questão de colocar entre aspas. Se em Bloch as respostas para tal reação estão evidenciadas em sua concepção de interdisciplinaridade e de demarcação dos objetos de cada ciência, Febvre explanará com clareza meridiana o que ele pensa dos termos acima e de seus significados. Em segundo, aparece outra vez a influência do pensamento alemão: a referência a Ratzel é inequívoca.

Uma vez que admitamos que o exame das relações homem-meio está longe de ter sido domínio exclusivo da Geografia, mas sim um verdadeiro paradigma a incidir sobre as Ciências Humanas na França da primeira metade do século $\mathrm{XX}$, não podia deixar de aparecer a recusa total e irrestrita ao determinismo geográfico. Sua máxima de que os fatores naturais limitavam as ações humanas de forma irreversivel lhe era alheia não apenas como argumento empírico, mas como premissa metodológica que, assentada num gênero de reducionismo, soava incompativel com a pluricausalidade histórica e o resgate da totalidade das experiências humanas defendidas por ele e Febvre. Sim, ele sabe que os próprios geógrafos já trataram de rechaçá-10 ${ }^{47}$. Mas nem por isso se abstém de fazê-lo à sua maneira: entrelaçando fato histórico e fato psicológico - ou seja, sublinhando a dimensão social e mental das ações humanas -, dirá que:

O virus da peste negra foi a causa primordial do despovoamento da Europa. Mas a epidemia só se propagou tão rapidamente em razão de certas condições sociais, portanto, em sua natureza profunda, mentais, e seus efeitos morais explicamse apenas pelas predisposições particulares da sensibilidade coletiva. São constatações dessa ordem que arruinaram o pseudo-determinismo geográfico. Às mesmas circunstâncias

\footnotetext{
${ }^{46}$ BLOCH, Op. Cit., 2001 (1949), p.131.

${ }^{47}$ BLOCH, Op. Cit., 1936, p.265.
} 
de clima, solo e localização, peritos diversamente preparados opõem reações bem diferentes. O deserto não é mais necessariamente 'monoteísta', assim como os povos dos litorais recortados não são, por uma inelutável fatalidade, povos de marinheiros ${ }^{48}$.

No entanto, isso não significa deixar de lado o devido papel dos fatores geográficos: na introdução metodológica de seu clássico sobre a história rural francesa, ele se ressente de que um livro de sintese e generalista precise abrir mão dos "fatores geográficos". Pois, se é verdade que eles não explicam os traços principais do tema em voga, possuem toda relevância quando se trata de perscrutar as diferenças entre as regiões ${ }^{49}$. Por fatores geográficos lê-se aspectos naturais, posto que sabemos o sentido que ele empresta às características geográficas na análise regional (vide o exemplo da Ile-de-France anteriormente citado). Eles são importantes por permitir uma distinção visivel das regiões, uma distinção "primeira" (digamos assim) que servirá como ponto de partida para a compreensão de assuntos como a ocupação do solo, tipos de cultura animal/vegetal, utilização de aparatos técnicos etc. Distribuídos em sítios diversos, os grupamentos humanos assumirão hábitos igualmente diversos. Tudo isso conforma um mosaico regional que jogará posição de relevo no âmbito da multissecular formação territorial francesa. Afinal, diferentes espaços (e fenômenos) possuem diferentes temporalidades ${ }^{50}$.

\footnotetext{
${ }^{48}$ BLOCH, Op. Cit., 2001 (1949), p.157.

${ }^{49} \mathrm{BLOCH}$, Marc. Les grandes étapes de l'occupation du sol. In: BLOCH, Marc. Les caractères originaux de l'histoire rurale française. $5^{\mathrm{a}}$ ed. Paris: Armand Colin (1968 [1931]), p.X.

50 "Quando se abria o período que chamamos Idade Média, quando, lentamente, começaram a se constituir um Estado e um agrupamento nacional que pode se qualificar de francês, a agricultura já era, sobre nosso solo, coisa milenar". In: BLOCH, Op. Cit., 1968 (1931), p.2.
} 


\section{A Geografia testemunha a História: paisagem, região e interdisciplinaridade em Marc Bloch}

Guilherme Ribeiro

Resumo: A proposta deste artigo é discutir a presença da geografia no pensamento do historiador francês Marc Bloch (1886-1944), co-fundador dos Annales ao lado de Lucien Febvre em 1929. Em oposição ao que a historiografia tem dito habitualmente, cremos que a geografia teve papel fundamental no desenvolvimento e na elaboração da nova escrita histórica praticada pelos Annales. Na reflexão de Bloch, é possivel observar tal aspecto através dos conceitos de paisagem e região, reveladores também da noção de interdisciplinaridade por ele praticada.

Palavras-chave: Annales; geografia; interdisciplinaridade; paisagem; região.

Abstract: This article has as a proposal the discussion about the presence of the Geography in the French historian Marc Bloch's thought (1886-1944), co-founder of the Annales beside Lucien Febvre in 1929. In opposition to the present historiography speech, we believe that Geography had a fundamental role in the development and the elaboration of the new historical writting practised by the Annales. In the Bloch's reflexion, we can see this aspect through the concepts of landscape and region, which they reveal the idea of interdisciplinarity worked by him.

Keywords: Annales; geography; interdisciplinarity; landscape; region.

Artigo recebido para publicação em 14/09/2009

Artigo aprovado para publicação em 18/11/2009 